\title{
MiscellaneOUS
}

\section{Bull's Eye: Unraveling the Medical Mystery of Lyme Disease}

\author{
By Jonathan A. Edlow. Second Edition, 2004. Yale Universi- \\ ty Press, New Haven and London. 304 pages. U.S.\$29.95 \\ Paper.
}

There have been few newly-emerging infectious diseases that have generated as much controversy as to their etiology and treatment as Lyme disease. From the "conventional" viewpoint, the disease is easily and accurately diagnosed, and short-term antibiotic treatment is effective; in the "alternative" point of view, the diagnosis of late-presenting cases is often missed due to inaccurate diagnostic tests, and long-term antibiotic treatment of such cases is necessary for a cure. This readable book gives a fair and balanced account of the differing points of view of these two camps. It covers the history of the discovery of Lyme disease, the elucidation of its causative agent, and the development of diagnostic tests and of treatments for the disease.

The disease was first recognized in North America when, around 1975, doctors at the Yale University School of Medicine noticed a new array of symptoms in patients from the area of Lyme, Connecticut. These symptoms consisted of a growing, ring-shaped rash (the bull's-eye) at the site of a tick bite, and swollen joints. Sometimes the rash and the arthritis had appeared without the patient's being aware of a tick bite.

The author, Jonathan Edlow, M.D., is Vice-Chairman of the Department of Emergency Medicine, Beth Israel Deaconess Medical Center, and Assistant Professor of Medicine, Harvard Medical School. He himself describes the book as "a medical detective story" that flowed from a combination of his interest in infectious diseases, and the fact that relatives of his who had moved to the Lyme area in the 1980s were stricken with symptoms of a bizarre arthritis, and/or rashes following tick bites.

The author starts with a detailed and interesting account of how, in the 1970s, residents of the Lyme area were experiencing a baffling array of physical symptoms, including rashes, unexplained neurological symptoms and swollen joints, that eluded diagnosis by their family doctors. Then two women, who together with their families and neighbours, had been ill for several years, were separately urged by their doctors to visit the Rheumatology Clinic at the Yale School of Medicine in New Haven. After hearing their stories, the doctors at the clinic realized that about thirty-five cases clustered in the Lyme area were presenting similar symptoms, and that an investigation into "what was happening at Lyme" was required. At the same time, U.S. Navy doctors at the nearby base in Groton, Connecticut, observed several patients with ring-shaped rashes which spread over a large area. Their case report in The Journal of the American Medical Association (JAMA), was read by a family doctor at the eastern end of Long Island who had patients with tick bites surrounded by a rash, who thought that his patients might have the same disease. He realized it was similar to a disease that had been recognized in Europe since 1910 as erythema migrans (EM). In the European reports, the disease was associated with tick bites and thought to have a spirochaete as the causative agent.

Having set the scene, the author describes the isolation of this causative agent by Willy Burgdorfer at the Rocky Mountain Laboratories, U.S. Public Health Service, who demonstrated that a spirochaete found in the deer tick, Ixodes scapularis, caused Lyme disease. The organism was later named Borrelia burgdorferi in his honour. But this tick can carry other pathogens (e.g., Babesia spp.) causing a co-infection in some patients, complicating both diagnosis and treatment. He further describes how, over time, a definite schism arose between the two groups of doctors maintaining the differing viewpoints mentioned. Patient advocacy groups arose who mainly supported the "alternative" position and, in 1993, a U.S. Senate Committee held hearings on the subject. The author sums up the current position by saying that debate remains about the best way to diagnose the disease, the utility of longterm antibiotic treatment, and the safety of a vaccine.

A drawback in the author's style arises when he uses analogies to try to explain scientific concepts. One example is that of a five-page description (complete with 5 Tables!) of the separation of peaches, apples, oranges and nectarines by machine, in an attempt to explain the meaning of the terms sensitivity and specificity in assessing the accuracy of laboratory tests. The result is confusion.

Appendix A lists the symptoms of Lyme disease, Appendix B lists tick-borne diseases in humans and animals. The book does not have a bibliography but, following the appendices, gives a list of sources for each chapter.

PEARL PETERKIN \#801 - 240 Brittany Drive, Ottawa, Ontario K1K 0R7 Canada

\section{The Importance of Species: Perspective on Expendability and Triage}

Edited by Peter Kareiva and Simon A. Levin. Princeton University Press, 41 William Street, Princeton, New Jersey 08540. 427 pages. U.S.\$53.00 Paper.

The ecological impact of the economic system we subscribe to could be viewed as the largest of all pos- sible species removal experiments. Unfortunately for us, this experiment is unreplicatable — we only get one shot at it. From the mid-point things don't look good. When the consequences of our personal actions and public policies are compared to the cataclysmic impact 